\title{
Comparison of the vaginal microbiota diversity of women with and without human papillomavirus infection: a cross-sectional study
}

Weijiao Gao', Jinlong Weng ${ }^{2}$, Yunong Gao ${ }^{1 *}$ and Xiaochi Chen ${ }^{3^{*}}$

\begin{abstract}
Background: The female genital tract is an important bacterial habitat of the human body, and vaginal microbiota plays a crucial role in vaginal health. The alteration of vaginal microbiota affects millions of women annually, and is associated with numerous adverse health outcomes, including human papillomavirus (HPV) infection. However, previous studies have primarily focused on the association between bacterial vaginosis and HPV infection. Little is known about the composition of vaginal microbial communities involved in HPV acquisition. The present study was performed to investigate whether HPV infection was associated with the diversity and composition of vaginal microbiota.

Methods: A total of 70 healthy women (32 HPV-negative and $38 \mathrm{HPV}$-positive) with normal cervical cytology were enrolled in this study. Culture-independent polymerase chain reaction-denaturing gradient gel electrophoresis was used to measure the diversity and composition of vaginal microbiota of all subjects.

Results: We found significantly greater biological diversity in the vaginal microbiota of HPV-positive women $(p<0.001)$. Lactobacillus, including L. gallinarum, L. iners and L. gasseri, was the predominant genus and was detected in all women. No significant difference between HPV-positive and HPV-negative women was found for the frequency of detection of L. gallinarum ( $p=0.775)$ or L. iners $(p=0.717)$, but L. gasseri was found at a significantly higher frequency in HPV-positive women $(p=0.005)$. Gardnerella vaginalis was also found at a significantly higher frequency in HPV-positive women $(p=0.031)$. Dendrograms revealed that vaginal microbiota from the two groups had different profiles.

Conclusions: Our study is the first systematic evaluation of an association between vaginal microbiota and HPV infection, and we have demonstrated that compared with HPV-negative women, the bacterial diversity of HPV-positive women is more complex and the composition of vaginal microbiota is different.
\end{abstract}

Keywords: Bacterial vaginosis (BV), Human papillomavirus (HPV), Polymerase chain reaction-denaturing gradient gel electrophoresis (DGGE), Vaginal microbiota

\section{Background}

Microbes inhabit virtually all sites of the human body and play an important role in human health, yet we know relatively little about them. The Human Microbiome Project (HMP) [1], funded by the National Institutes of Health

\footnotetext{
* Correspondence: gaoyunong@vip.sina.com; chenxiaochi@pkuss.bjmu.edu.cn ${ }^{1}$ Key laboratory of Carcinogenesis and Translational Research (Ministry of Education), Department of Gynecologic Oncology, Peking University school of Oncology, Peking University Cancer Hospital and Institute, No 52, Fucheng Road, Haidian District, Beijing 100142, PR China

${ }^{3}$ Department of Oral Biology, Peking University School and Hospital of Stomatology, No 22, Zhongguancun Nandajie, Haidian District, Beijing 100081, PR China

Full list of author information is available at the end of the article
}

Roadmap for Biomedical Research, was implemented in 2007. To date, the HMP has released over 100 million $16 \mathrm{~S}$ rRNA gene reads and more than 8 trillion bytes of shotgun metagenomic sequences [2]. Studies of the gastrointestinal microbiota showed that bacteria maintain homeostasis with the host in a healthy gut [3]. However, when bacterial dysbiosis (microbial imbalance) occurs in the gut, the host may experience inflammation, a loss of barrier function, and possibly serious disease such as ulcerative colitis, Crohn's disease and colorectal cancer [4-6].

The female genital tract is an important habitat for human microbiota. Investigation of "normal" vaginal microbiota

\section{Biomed Central}

(c) 2013 Gao et al.; licensee BioMed Central Ltd. This is an Open Access article distributed under the terms of the Creative Commons Attribution License (http://creativecommons.org/licenses/by/2.0), which permits unrestricted use, distribution, and reproduction in any medium, provided the original work is properly cited. 
typically reveals Lactobacillus species as the predominance genus in the vagina, which helps to promote a healthy vaginal milieu [7]. Bacterial vaginosis (BV), characterized by a loss of indigenous Lactobacillus species and a concurrent overgrowth of anaerobic bacteria, has been associated with vaginal discharge syndrome, poor pregnancy outcomes, pelvic inflammatory disease, post-operative wound infections, and endometritis after elective abortions [8-11]. Additionally, BV predisposes women to infection by human papillomavirus (HPV) [12]. Guo et al. [13] reported that compared with women without BV, those with BV had a lower clearance of HPV. And Dols et al. [14] resisted that in women with HPV infection, the prevalence of L. crispatus was significantly reduced and there was a shift in the composition of the Lactobacillus microbiota in HPV infection.

Persistent HPV infection is the central factor in the development of cervical cancer, and is a prerequisite for progression to high-grade cervical lesions [15]. However, few HPV infections progress to cervical cancer, and most HPV infections are eventually cleared [16]. The reason(s) why high risk HPV infection is cancerous in some women but not others is unknown. Some studies imply that BV is associated with HPV acquisition; a meta-analysis of twelve studies with a total of 6,372 women indicated a positive association between BV and HPV infection, with an overall estimated odds ratio of 1.43 (95\% confidence interval, 1.11-1.84) [12]. However, these studies focused on the relationship between BV (diagnosed using clinical Amsel criteria or Nugent's score) and HPV infection $[17,18]$, and did not examine the composition of vaginal microbial communities involved in HPV acquisition.

It is difficult to assess the microbial community in an environment where more than $80 \%$ of microbiota is nonculturable (such as the vagina) $[19,20]$. However, the advances of molecular biotechnology, such as cultureindependent polymerase chain reaction-denaturing gradient gel electrophoresis (PCR-DGGE), enable better characterization of complex microbial communities $[21,22]$. The combination of PCR and DGGE allows for the rapid and reliable examination of the vaginal microbiota, and these techniques have been used widely in bacterial microbiota studies [23-25]. The method allows numerous samples to be screened, because the microbial nucleic can be derived directly from human specimens, without the need for culture enrichment. In addition, PCR-generated DNA fragments of the same length but different base-pair sequences can be separated by DGGE. Although PCRDGGE has some shortcomings, including the fact that it needs costly equipment, the "GC clamp" is very expensive, and the formamide is poisonous, it is a powerful tool for microbiota studies. But the next generation sequencing [26] might will replace the current molecular biotechnology in the near future.
To examine the relationship between the diversity and composition of vaginal microbiota and HPV positivity, we used PCR-DGGE to examine the vaginal microbiota of $38 \mathrm{HPV}$-negative and $32 \mathrm{HPV}$-positive healthy women with no BV (using Amsel criteria). To our knowledge, this is the first study of the association between HPV infection and vaginal microbiota to use a molecular biological technique to examine the microbiota.

\section{Methods}

\section{Subject selection}

A total of 100 healthy women (50 HPV-negative and 50 HPV-positive) with normal cervical cytology, who accepted a routine gynecological examination and Thinprep Cytology Test (TCT) in Beijing Cancer Hospital from January 2012 to June 2012, were initially recruited for this study. Subsequently, TCTs were reexamined by two cytologists and HPV infection was reexamined by PCR. If there was a difference between the first and second TCT reports, or between the results from the two cytologists performing the second TCT, the woman was excluded from the study. In addition, if a recruited woman was infected with more than one HPV type, or there was a difference between the initial HPV report using Hybrid Capture II and the second HPV report using PCR, the woman was excluded from the study. A total of 30 women were excluded from the study based on these four criteria. Inclusion criteria were age $<50$, no BV by the Amsel method, no use of antibiotics or vaginal antimicrobials (orally or by topical application in vulvar/vaginal area) in the previous month, and no vaginal intercourse or vaginal lavage within the last 3 days. All subjects were free of systemic diseases such as diabetes, autoimmune disease, and malignant tumors. Informed written consent was obtained from all participants prior to enrollment. This study was approved by the ethical committee of Peking University Cancer Hospital and Institute, Beijing, China.

\section{Sample collection and preparation}

When women underwent genital examination, a sterile swab sample was taken from near the vaginal fornix and cervix from each participant. The swab was placed into $1 \mathrm{ml}$ sterile saline, placed on ice packs immediately, and transferred to the laboratory within $30 \mathrm{~min}$. The sample was pelleted by centrifugation at $\geq 10,000 \times \mathrm{g}\left(25^{\circ} \mathrm{C}\right)$ for $10 \mathrm{~min}$ and stored at $-80^{\circ} \mathrm{C}$ until further analysis, as previously published [27].

\section{Total bacterial genomic DNA extraction}

Bacterial DNA was extracted according to the procedures described by Signoretto [28] and Zijnge [29]. Briefly, the sample was incubated for $1 \mathrm{~h}$ at $58^{\circ} \mathrm{C}$ with $1 \mathrm{ml}$ of lysis buffer (10\% SDS and $0.2 \mathrm{mg} / \mathrm{ml}$ proteinase $\mathrm{K}$ in $25 \mathrm{mM}$ 
Tris- $\mathrm{HCl}, \mathrm{pH} 8$ ). The sample was then incubated at $80^{\circ} \mathrm{C}$ for $10 \mathrm{~min}$ to inactivate the proteinase $\mathrm{K}$. DNA was purified from the lysate by repeated phenol-chloroformisoamyl alcohol extraction, precipitated with sodium acetate and ethanol, dissolved in $100 \mu \mathrm{l}$ sterile Milli-Q water and stored at $-20^{\circ} \mathrm{C}$ in aliquots. The concentration of extracted DNA was determined by a Nano Photometer ${ }^{\mathrm{TM}}$ Pearl ultramicro ultraviolet spectrophotometer (Implen, Munich, Germany). The quality of the DNA was checked by agarose gel electrophoresis. All DNA was stored at $20^{\circ} \mathrm{C}$ before further analysis.

\section{Nested PCR}

The hypervariable region chosen for amplification can influence the PCR-DGGE profiles. The V2-V3 region of the $16 \mathrm{~S}$ rRNA gene is reported to be the most reliable $[30,31]$. The consensus primers used in this study were as follows: S-D-Bact -0008-a-S-20/ S-*-Univ-1492-b-A21: AGA GTT TGA TCC TGG CTC AG/ ACG GCT ACC TTG TTA CGA CTT; and HDA1- GC/ HDA2: CGC CCG GGG CGC GCC CCG GGC GGG GCG GGG GCA CGG GGG GAC TCC TAC GGG AGG CAG CAG/ GTA TTA CCG CGG CTG CTG GCA. The primers used in this study have been published previously [32,33].

The first PCR mixture contained 100 ng of DNA template, $5 \mathrm{pmol}$ of each primer, $25 \mu \mathrm{l}$ of $2 \times$ PCR Master Mix (0.05 unit/ $\mu$ Taq DNA Polymerase, $4 \mathrm{mM} \mathrm{MgCl}_{2}$, 0.4 mM dATP, $0.4 \mathrm{mM}$ dCTP, $0.4 \mathrm{mM}$ dGTP, 0.4 mM dATP and 0.4 mM dTTP) (Fermentas, Vilnius, Lithuania) and RNase-free $\mathrm{H}_{2} \mathrm{O}$ in a final volume of $50 \mu \mathrm{l}$. The cycling parameters were $95^{\circ} \mathrm{C}$ for $5 \mathrm{~min} ; 25$ cycles of $95^{\circ} \mathrm{C}$ for $2 \mathrm{~min}, 42^{\circ} \mathrm{C}$ for $30 \mathrm{~s}, 72^{\circ} \mathrm{C}$ for $4 \mathrm{~min}$; and a final cycle of $72^{\circ} \mathrm{C}$ for $20 \mathrm{~min}$. The temperature was held at $4^{\circ} \mathrm{C}$ following the final cycle [34].

The second PCR mixture contained $5 \mu \mathrm{l}$ of PCR product from the above reaction, $10 \mathrm{pmol}$ of each primer, $25 \mu \mathrm{l}$ of $2 \times$ PCR Master Mix (0.05 unit/ $\mu$ l Taq DNA Polymerase, $4 \mathrm{mM} \mathrm{MgCl}_{2}, 0.4 \mathrm{mM}$ dATP, $0.4 \mathrm{mM}$ dCTP, $0.4 \mathrm{mM}$ dGTP, 0.4 mM dATP and 0.4 mM dTTP) and RNase free $\mathrm{H}_{2} \mathrm{O}$ in a final volume of $50 \mu \mathrm{l}$. The cycling parameters were $95^{\circ} \mathrm{C}$ for $5 \mathrm{~min} ; 30$ cycles of $95^{\circ} \mathrm{C}$ for $30 \mathrm{~s}, 56^{\circ} \mathrm{C}$ for $30 \mathrm{~s}, 72^{\circ} \mathrm{C}$ for $1 \mathrm{~min}$; and a final cycle of $72^{\circ} \mathrm{C}$ for $8 \mathrm{~min}$. The temperature was held at $4^{\circ} \mathrm{C}$ following the final cycle [35].

\section{DGGE}

The denaturing gradient gel was formed with $8 \%$ polyacrylamide stock solution containing either low (40\%) or high $(70 \%)$ concentrations of urea and formamide that increased in the direction of electrophoresis.

PCR products were mixed with a loading buffer containing bromophenol blue, xylene cyanol, and 70\% glycerol in TAE buffer $(0.02 \mathrm{M}$ Tris base, $0.01 \mathrm{M}$ acetic acid, $1 \mathrm{mM}$ EDTA, pH 7.5) and loaded into the gels. About $20 \mu \mathrm{l}$ of the reference mixture was combined with loading buffer, and the mixture was loaded so that it flanked the vaginal samples. Electrophoresis was performed for $16 \mathrm{~h}$ at $60 \mathrm{~V}$ and $58^{\circ} \mathrm{C}$. The gels were stained with SYBR Green I $(1: 10,000)$ for $30 \mathrm{~min}$.

DGGE images were digitally captured and recorded by the BIO-RAD Gel Doc ${ }^{\mathrm{Tm}} \mathrm{XR}^{+}$Gel Imaging System (Bio-Rad, Hercules, USA) and analyzed by Gel Compare ${ }^{\bullet}$ (Applied Maths, Kortrijk, Belgium). Each gel was normalized according to a DGGE standard marker (10 markers according to the $\mathrm{GC}$ base-pair percentage).

\section{Cloning of excised DGGE bands}

The main DGGE bands were excised, and the DNA fragments were amplified with primers HDA1 (without the CG clamp) and HDA2. Amplified material was cloned into the $\mathrm{pGM}^{\ominus}-\mathrm{T}$ vector using the $\mathrm{pGM}^{\circ}-\mathrm{T}$ cloning Kit (Tiangen, Beijing, China), according to the manufacturer's instructions. The vector was then cloned into Escherichia coli Top10, and the extracted plasmid was sequenced by the Beijing Genomics Institute. Sequence identification of the plasmid was performed by searching the NCBI BLAST database.

\section{Detection of HPV}

HPV DNA was extracted from the remnant TCT sample by TIANamp Virus DNA/RNA Kit (Tiangen) according to the manufacturer's instructions. HPV DNA was first amplified using the HPV L1 consensus MY09/MY11 primer pair, followed by nested PCR with GP5+/GP6+ primers. The PCR amplification was performed as described previously [36,37].

PCR products were subjected to direct DNA sequencing by the Beijing Genomics Institute. The obtained sequences were compared with documented virus sequences available in the GenBank database using the BLAST program. The subjects whose results were different to the previous results from Hybrid Capture or who were infected with multiple HPV genotypes were eliminated from this study. HPV-negative women and women infected with one HPV (single high-risk) subtype were included in this study. The HPV types are not listed in this paper.

\section{Statistical analysis}

The similarities of PCR-DGGE DNA profiles were analyzed with Gel Compare ${ }^{\curvearrowleft}$ software (Applied Maths) using Dice's similarity coefficient. The clustering algorithm, unweighted pair-group method with arithmetic means (UPGMA), was used to calculate the dendrogram.

Vaginal microbiota diversity was expressed by the Shannon-Weiner diversity index [38-40] and calculated using the following formula: $H^{\prime}=-\Sigma p_{i} \ln p_{i}$. For morphological analysis, $p_{i}$ is the proportion of individuals in the 
$i$ th taxon. For PCR-DGGE analysis, $p_{i}$ is the importance probability of the bands in a gel lane and measured as $p_{i}=n_{i} / N$, where $n_{i}$ is the intensity of a band and $N$ is the sum of all band intensities in the densitometry profile. The Mann-Whitney $U$ test and Kruskal-Wallis tests were performed to compare the diversity indices, and $p<0.05$ was interpreted to be statistically significant.

\section{Results}

DGGE profiles in HPV-positive and HPV-negative women A total of $38 \mathrm{HPV}$-negative women (mean age 37.0) and 32 HPV-positive women (mean age 37.8) were enrolled in this study. There was no significant difference in age between the two groups $(p=0.57)$.
The DGGE profiles of vaginal samples were obtained from all 70 women. Figure 1 shows representative DGGE profiles of vaginal microbiota from the two groups. The left panel depicts DGGE profiles from five HPV-negative women (N1-N5) and the right panel shows profiles from five $\mathrm{HPV}$-positive women ( $\mathrm{H} 1-\mathrm{H} 5)$. Lane $\mathrm{M}$ comprises 10 markers $(a-j)$, and the bands of each lane in each DGGE profile are classified by each marker's GC base-pair percentage. The bilateral part of the figure shows the marker files from different DGGE gels. Each gel was normalized according to a DGGE standard marker, and each peak in the marker files stands for one marker. Pairwise comparisons between each gel marker using Gel Compare ${ }^{\curvearrowright}$ software demonstrated that the marginal discrepancies of marker bands between each gel are negligible.

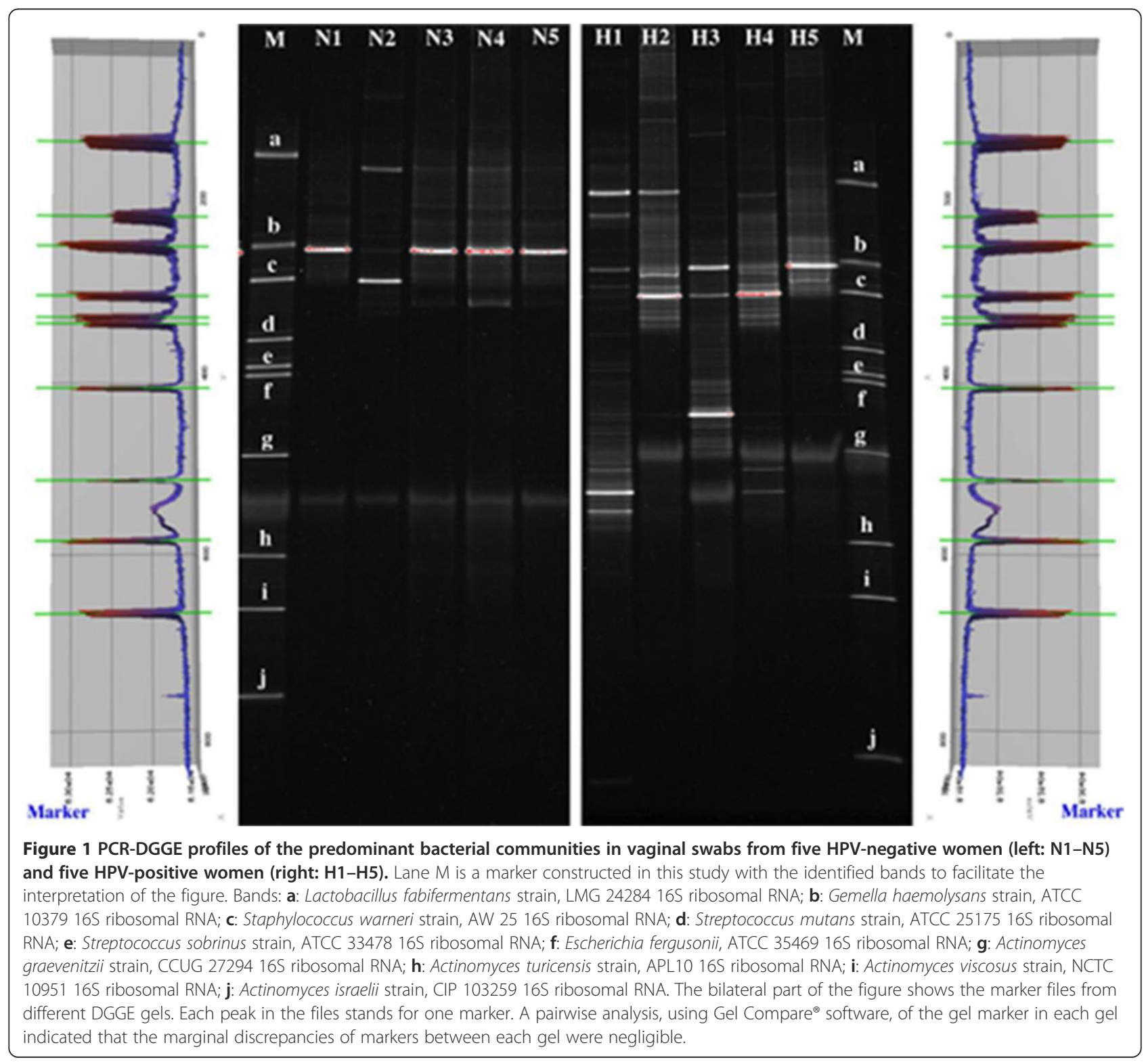


The number of bands in the DGGE profile from each woman is shown in Table 1. Previous studies have reported that healthy vaginal microbiota only contains one or two predominant species $[41,42]$. We compared the number of bands in samples from HPV-positive women versus HPV-negative women. Half of the vaginal samples from HPV-negative women contained more than two bands in their DGGE profiles, whereas $87.5 \%$ of HPV-positive women had more than two bands. The mean band number from HPV-negative women was 3.45, and the mean number from HPV-positive women was 6.47 (Chi-squared test, $p=0.001$ ).

Vaginal microbiota diversity was expressed using the Shannon-Weiner diversity index and compared using the Mann-Whitney U test. The diversity index for subjects with and without HPV infection is displayed in Figure 2 . We found significantly greater biological diversity in HPV-positive women (mean $=1.64$; range, 0 to 3.09 ) than in HPV-negative women (mean $=0.93$; range, 0 to 2.62) $(p<0.001)$.

\section{Cluster analysis based on DGGE profiles}

The UPGMA clustering algorithm was used to construct a dendrogram of the DGGE profiles of vaginal microbiota from all 70 women enrolled in this study. Hierarchical cluster analysis of the dendrogram indicated that six clusters were formed, and revealed differences in the composition of vaginal microbiota between HPV-negative women and HPV-positive women (Figure 3). Most samples from HPV-positive women fell within clusters 1-4. Conversely, clusters 5 and 6 primarily comprised samples from HPVnegative women. There were significantly more bands in cluster 1-4 than in clusters 5 and 6 , indicating that the vaginal microbiota of HPV-positive women had a greater biological diversity than that of HPV-negative women. Of note, in cluster 6 the DGGE profiles consisted of only one or two bands.

The discriminative character analysis of DGGE profiles showed that the bands in box A are present in both HPVpositive and HPV-negative women (Figure 3). However, the bands in box B mostly appeared in cluster 2 (which primarily consists of HPV-positive women). The bands in box $\mathrm{C}$ were detected in cluster 2 , cluster 3 , and other

Table 1 Comparison of number of bands between HPVnegative women and HPV-positive women

\begin{tabular}{ccccc}
\hline & \multicolumn{2}{c}{ Case number (n and percentage) } & \multirow{2}{*}{ P value $^{*}$} \\
\cline { 2 - 4 } & HPV-negative & HPV-positive & Total & \\
\hline 0-2 bands & $19(50 \%)$ & $4(12.5 \%)$ & $23(32.9 \%)$ & 0.001 \\
over 2 bands & $19(50 \%)$ & $28(87.5 \%)$ & $47(67.1 \%)$ & \\
\hline
\end{tabular}

* The Chi-squared test was used to compare the proportion of samples in each category for HPV-negative women versus HPV-positive women. $p<0.05$ was considered statistically significant.

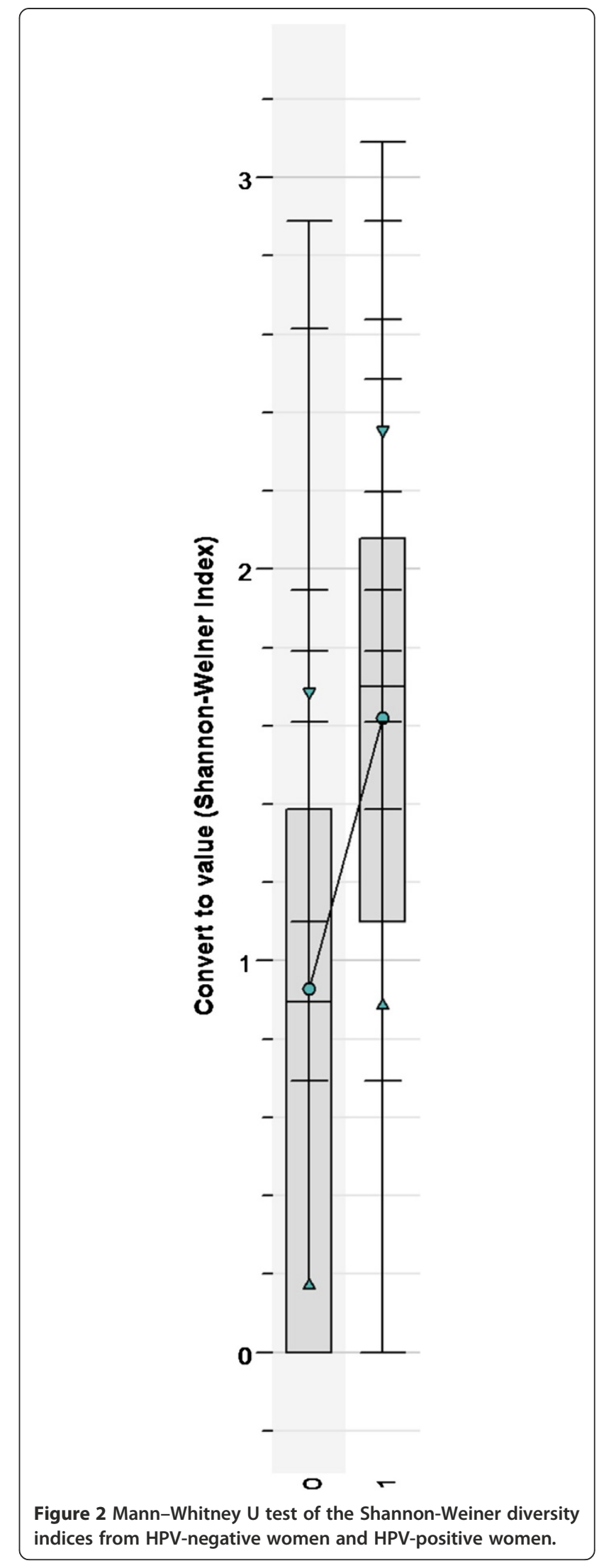

Figure 2 Mann-Whitney $U$ test of the Shannon-Weiner diversity indices from HPV-negative women and HPV-positive women. 


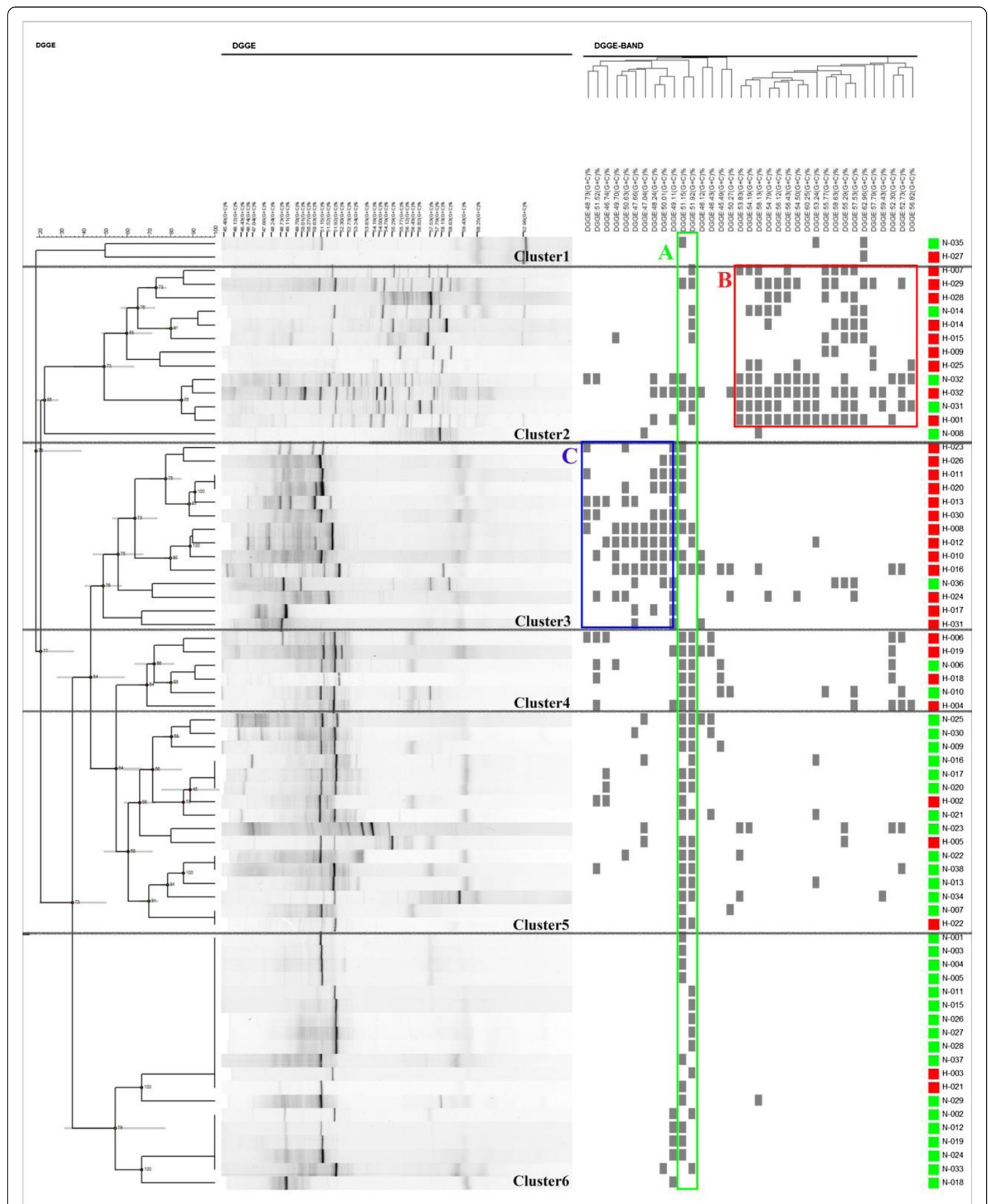

Figure 3 Hierarchical cluster analysis and discriminative characters analysis of all DGGE profiles. HPV-negative women are green and HPV-positive women are red. The box around bands $\mathbf{A}$ is green, the box around bands $\mathbf{B}$ is red, and the box around bands $\mathbf{C}$ is blue. 
clusters, but the bands in box $\mathrm{C}$ are mostly from HPVpositive women.

We compared the number of bands, Shannon-Weiner diversity index and the proportion of samples from HPVpositive and HPV-negative women in each of the six clusters (Table 2). There were large differences in all three characteristics (all $p$ values $<0.001$ ). The Kruskal-Wallis test was used to compare the Shannon-Weiner diversity indices from each of the six clusters, and we found that the diversity of at least one of the clusters was significantly different from the other clusters $(p<0.001)$.

\section{Identification of vaginal microorganisms}

Excised DGGE gel bands were sequenced and BLAST database searches were used to identify 18 bacterial species present in vaginal samples from the 70 women studied. The name of each microorganism, sequence identities and NCBI Sequence ID are shown in Table 3. The sequence identities of most microorganism were above $97 \%$.

Lactobacillus was the most predominant genus, and was detected in all women included in this study. The Lactobacillus members are grouped into three species: L. gallinarum was the most abundant $(45 / 70,64 \%)$, followed by L. iners $(41 / 70,59 \%)$ and L. gasseri $(23 / 70,33 \%)$ (Table 4). The next most predominant genus was Gardnerella vaginalis (14/70, 20\%), followed by Atopobium vaginae (7/70, 10\%). A Chi-squared analysis revealed that there is no difference in the frequency of identification of L. gallinarum between HPV-negative and HPV-positive women $(p=0.775)$. Likewise, no significant difference existed in the frequency of identification of $L$. iners $(p=0.717)$ or Atopobium vaginae $(p=0.150)$. However, $L$. gasseri and Gardnerella vaginalis were isolated more frequently in HPV-positive women than in HPV-negative women ( $p=$ 0.005 and $p=0.031$, respectively).

L. gallinarum and L. iners are the two bands in box A of Figure 3. Gardnerella vaginalis is the predominant genus of the bands in box B, and other bands in box B include Escherichia fergusonii, Atopobium vaginae, Streptococcus australis, Streptococcus intermedius and Alloscardovia omnicolens. L. gasseri is the predominant genus of the bands in box $\mathrm{C}$, and another band in box $\mathrm{C}$ is ureaplasma parvum serovar 3 str.

\section{Discussion}

Biologic susceptibility to HPV acquisition and immune competence for clearance of an HPV infection can be affected by vaginal bacterial infection, which disrupts the balance of vaginal microbiota [12,43]. Previous studies have not investigated the difference in microbiota communities between HPV-negative and HPV-positive women. To our knowledge, the current study is the first systematic evaluation of an association between vaginal microbiota and HPV infection. Our study analyzes the diversity and abundance of the vaginal microbiota by PCR-DGGE, and compares the microbiota by HPV infection status. This study may be helpful to reveal the role of the vaginal microbiota in the natural history of HPV infection.

If the target $16 \mathrm{~S}$ rRNA gene copy number in the sample is low, it is likely that it cannot be amplified sufficiently to be visualized as a band. Therefore, the bands generated in DGGE reflect the most abundant genus from each vaginal sample [44]. In our study, the number of DGGE bands in HPV-positive women was significantly higher than that in HPV-negative women. Therefore, we conclude that the vaginal microbiota of HPV-infected women is more complex than that of HPV-negative women in our study.

The Shannon-Weiner diversity index uses the total number and relative intensities of DGGE bands, which makes it more suitable to estimate bacterial diversity than the number of bands alone [45]. A Mann-Whitney U test comparing the Shannon-Weiner diversity index between HPV-positive and HPV-negative women demonstrated that there was significantly greater biological diversity in HPV-positive women than HPV-negative women $(p<0.001)$. Other studies have also demonstrated a difference in the abundance of bacterial species present in the vagina when comparing healthy women to those with $\mathrm{BV}$ or cervicitis $[25,46]$. This suggests that an increase in bacterial diversity may be associated with the shift from health to disease. Of note, the opposite is true for oral

Table 2 Comparison of the number of bands, Shannon-Weiner diversity index and the proportion of samples in each cluster

\begin{tabular}{|c|c|c|c|c|c|c|c|c|}
\hline & & Cluster 1 & Cluster 2 & Cluster 3 & Cluster 4 & Cluster 5 & Cluster 6 & $P$ value \\
\hline Number of bands & & $2.00 \pm 1.414$ & $9.69 \pm 6.223$ & $6.36 \pm 3.054$ & $6.17 \pm 1.329$ & $4.13 \pm 2.187$ & $1.32 \pm 0.478$ & $<0.001^{*}$ \\
\hline Shannon-Weiner index & & $0.55 \pm 0.777$ & $2.07 \pm 0.717$ & $1.75 \pm 0.469$ & $1.80 \pm 0.214$ & $1.23 \pm 0.293$ & $0.22 \pm 0.331$ & $<0.001^{\#}$ \\
\hline \multirow[t]{3}{*}{ Group } & HPV-negative & $1(50.0 \%)$ & $4(30.8 \%)$ & $1(7.1 \%)$ & $2(33.3 \%)$ & $13(81.3 \%)$ & 17 (89.5\%) & \\
\hline & HPV-positive & $1(50.0 \%)$ & $9(69.2 \%)$ & $13(92.9 \%)$ & $4(66.7 \%)$ & $3(18.7 \%)$ & $2(10.5 \%)$ & $<0.001^{*}$ \\
\hline & Total & $2(2.9 \%)$ & $13(18.6 \%)$ & $14(20.0 \%)$ & $6(8.6 \%)$ & $16(22.9 \%)$ & 19 (27.1\%) & \\
\hline
\end{tabular}

*The Chi-squared test was used to compare the proportion of samples in each category for HPV-negative versus HPV-positive women. $p<0.05$ was considered statistically significant.

\# The Kruskal-Wallis test was performed to compare the diversity indices, and $p<0.05$ was interpreted to be statistically significant. 
Table 3 Microorganisms identified in the vaginal tract of all 70 women

\begin{tabular}{|c|c|c|c|}
\hline $\begin{array}{c}\text { Name of } \\
\text { microorganism }\end{array}$ & $\begin{array}{c}\text { Identity } \\
\%\end{array}$ & $\begin{array}{l}\text { Sequence } \\
\text { length }\end{array}$ & $\begin{array}{c}\text { Genbank accession } \\
\text { numbers }\end{array}$ \\
\hline Aeromicrobium spp. & 92 & 154 & -— \\
\hline $\begin{array}{l}\text { Alloscardovia } \\
\text { omnicolens }\end{array}$ & 99 & 152 & NR_042583.1 \\
\hline Atopobium vaginae & 97 & 151 & NR_029349.1 \\
\hline $\begin{array}{l}\text { Bifidobacterium } \\
\text { scardovii }\end{array}$ & 98 & 152 & NR_025452.1 \\
\hline Escherichia fergusonii & 99 & 172 & NR_027549.1 \\
\hline Finegoldia magna & 99 & 148 & NR_041935.1 \\
\hline Gardnerella vaginalis & 99 & 154 & NR_044694.1 \\
\hline $\begin{array}{l}\text { Lactobacillus } \\
\text { gallinarum* }\end{array}$ & 99 & 174 & NR_042111.1 \\
\hline Lactobacillus gasseri & 99 & 172 & NR_041920.1 \\
\hline Lactobacillus iners & 98 & 168 & NR_036982.1 \\
\hline Nocardia spp. & 90 & 153 & - - \\
\hline $\begin{array}{c}\text { Peptostreptococcaceae } \\
\text { bacterium }\end{array}$ & 99 & 146 & NR_041586.1 \\
\hline Prevotella spp. & 96 & 163 & - - \\
\hline Pseudobutyrivibrio spp. & 96 & 146 & -— \\
\hline $\begin{array}{l}\text { Streptococcus } \\
\text { agalactiae }\end{array}$ & 99 & 168 & NR_040821.1 \\
\hline Streptococcus australis & 98 & 173 & NR_036936.1 \\
\hline $\begin{array}{l}\text { Streptococcus } \\
\text { intermedius }\end{array}$ & 99 & 171 & NR_028736.1 \\
\hline $\begin{array}{l}\text { Ureaplasma parvum } \\
\text { serovar } 3 \mathrm{str} .\end{array}$ & 99 & 169 & NR_027532.1 \\
\hline
\end{tabular}

*The result of a BLAST search indicated that the similarity score of $L$. gallinarum was same as other Lactobacillus spp., such as L. crispatus, L. acidophilus, L. amylovorus, L. rhamnosus, L. fermentum, L. helveticus, L. kitasatonis and L. ultunensisc.

health, where a decrease in bacterial diversity is associated with disease [47].

The UPGMA clustering algorithm has been used previously [48], and in our study it was used to identify samples that generate similar DGGE profiles. The UPGMA dendrogram showed that six distinct clusters are formed,

Table 4 Number of times the main genus was identified in HPV-negative women and HPV-positive women

\begin{tabular}{lccc}
\hline Name of microorganism & \multicolumn{2}{c}{ Times identified in women } & P value \\
\cline { 2 - 3 } & $\begin{array}{c}\text { HPV-negative } \\
(\mathbf{n}=\mathbf{3 8})\end{array}$ & $\begin{array}{c}\text { HPV-positive } \\
(\mathbf{n}=\mathbf{3 2})\end{array}$ & \\
\hline Lactobacillus gallinarum & 25 & 20 & 0.775 \\
Lactobacillus iners & 23 & 18 & 0.717 \\
Lactobacillus gasseri & 7 & 16 & 0.005 \\
Gardnerella vaginalis & 4 & 10 & 0.031 \\
Atopobium vaginae & 2 & 5 & 0.150 \\
\hline
\end{tabular}

* The Chi-squared test was used to compare the times of the main genus identified in HPV-negative women and HPV-positive women. $p<0.05$ was considered statistically significant. and that samples from HPV-positive and HPV-negative women tend to be in distinct clusters. The discriminative characters analysis of DGGE profiles indicate that the bands of box B and box $C$, which are different in clusters 1-4 versus cluster 5-6, might generate the distinction of clusters.

Over 120 species of Lactobacillus have been identified, and more than 20 species have been detected in the vagina. However, vaginal microbiota is not reported to contain very many different species of Lactobacillus [49]. Typically, one or two Lactobacilli species are predominant. For example, L. crispatus and $L$. jensenii were the most common genera for white women [50], while L. crispatus and L. gasseri were more common in Japanese women [51]. Recently, a study from China reported that L. crispatus, L. iners and L. gasseri were the most common genera in Chinese women [52].

In our study, sequence analysis identified three Lactobacillus members: L. gallinarum, L. iners and L. gasseri, all of which are obligately homofermentative species. L. gallinarum and L. iners are the two bands in box A (Figure 3), and there was no difference between HPVnegative women and HPV-positive women, there was no difference among each cluster. However, L. gasseri is the main species in box $\mathrm{C}$, and was detected more frequently in the HPV-positive women $(p=0.005)$. Cherpes et al. reported that $L$. gasseri was vaginal colonization from the rectum [53], and a study of homosexual women found an association between L. gasseri and BV [54]. And Dols et al. [14] resisted that the prevalence of L. crispatus was significantly reduced and there was a shift in the composition of the Lactobacillus microbiota in women with HPV infection.

But we were not able to distinguish L. gallinarum from the other Lactobacillus spp., because the BLAST result indicated that the similarity score of L. gallinarum was the same as that of other Lactobacillus spp., such as $L$. crispatus, $L$. acidophilus, $L$. amylovorus, L. rhamnosus, L. fermentum, L. helveticus, L. kitasatonis and L. ultunensis. One possible explanation for this is that the genera of Lactobacillus spp. mentioned above have the same DNA sequence as L. gallinarum in the V2-V3 region of $16 \mathrm{~S}$ rDNA. Future research will seek to resolve this issue.

The bands in box B are the primary bands that distinguish cluster 2 from other clusters. The main microorganisms in box B are Gardnerella vaginalis and Atopobium vaginae. Gardnerella vaginalis is a facultative anaerobic bacterium of the Bifidobacteriaceae family [55], while the genus Atopobium lies within the family Coriobacteriaceae and forms a distinct branch within the phylum Actinomycetes [56]. Because Gardnerella vaginalis and Atopobium vaginae were frequently detected in association with $\mathrm{BV}$, Menard deemed the combination of the two bacterial genera as predictive criteria for the diagnosis of BV [57]. In 
our study, Gardnerella vaginalis (10/32 vs. 4/38, $p=$ $0.031)$ and Atopobium vaginae ( $2 / 38$ vs. $5 / 32, p=0.150)$ were more frequently detected in HPV-infected women than in HPV-negative women, though the difference of Atopobium vaginae in the two groups was not statistically significant.

Because this was a cross-sectional study, we were unable to determine whether a change in vaginal microbiota preceded HPV infection, or whether HPV infection preceded a change in vaginal microbiota. Furthermore, we initially recruited 100 women with normal cervical cytology and excluded 30 from the study, which led to a relatively small sample size. However, because this is the first study to use PCR-DGGE to examine the association between vaginal microbiota and HPV infection, even with the limitations mentioned above we believe it has substantial importance.

\section{Conclusion}

In conclusion, we found that the bacterial diversity and composition in HPV-positive women were more complex than in HPV-negative women. Gardnerella vaginalis and L. gasseri were detected significantly more frequently in HPV-positive women. Abnormal vaginal microbiota might act as a co-factor for the acquisition of HPV. Continued exploration of the interplay between vaginal bacterial communities and HPV may shed light on biologic susceptibility to HPV infection, as well as immune competence for clearance of HPV, which may provide new insights into the early steps in the development of cervical cancer.

\section{Abbreviations}

BV: Bacterial Vaginosis; DGGE: Denaturing Gradient Gel Electrophoresis; HPV: Human Papillomavirus; PCR: Polymerase Chain Reaction; HMP: the Human Microbiome Project; TCT: Thinprep Cytology Test;

UPGMA: Unweighted Pair-Group Method with Arithmetic Means.

\section{Competing interests}

The authors declare that they have no competing interests.

\section{Authors' contributions}

WJ Gao conducted the PCR-DGGE studies, performed the statistical analysis, participated in clinical sample collection and drafted the manuscript. JL Weng conducted the cloning of DNA fragments and participated in the statistical analysis. YN Gao and XC Chen conceived the study, participated in its design and coordination and helped to draft the manuscript. YN Gao carried out clinical sample collection and was responsible for clinical data. XC Chen helped conduct the molecular biological experiments and was responsible for the experimental data. All authors read and approved the final manuscript.

\section{Acknowledgments}

We thank all the volunteers involved in this study. This work was supported by a grant from Peking University Cancer Hospital, Beijing Cancer Hospital and Institute.

\section{Author details}

${ }^{1}$ Key laboratory of Carcinogenesis and Translational Research (Ministry of Education), Department of Gynecologic Oncology, Peking University school of Oncology, Peking University Cancer Hospital and Institute, No 52, Fucheng
Road, Haidian District, Beijing 100142, PR China. ${ }^{2}$ First Dental Clinic, Peking University School and Hospital of Stomatology, 37 Xishiku Dajie, Xicheng District, Beijing 100034, PR China. ${ }^{3}$ Department of Oral Biology, Peking University School and Hospital of Stomatology, No 22, Zhongguancun Nandajie, Haidian District, Beijing 100081, PR China.

Received: 19 February 2013 Accepted: 30 May 2013

Published: 10 June 2013

\section{References}

1. Turnbaugh PJ, Ley RE, Hamady M, Fraser-Liggett CM, Knight R, Gordon J: The human microbiome project. Nature 2007, 449:804-810.

2. Human Microbiome Project C: A framework for human microbiome research. Nature 2012, 486:215-221.

3. Mutch DM, Simmering R, Donnicola D, Fotopoulos G, Holzwarth JA, Williamson G, Corthesy-Theulaz I: Impact of commensal microbiota on murine gastrointestinal tract gene ontologies. Physiol Genomics 2004, 19:22-31.

4. Kaur N, Chen CC, Luther J, Kao JY: Intestinal dysbiosis in inflammatory bowel disease. Gut microbes 2011, 2:211-216.

5. Sasaki M, Klapproth JM: The role of bacteria in the pathogenesis of ulcerative colitis. Journal of signal transduction 2012, 2012:704953.

6. Sobhani I, Tap J, Roudot-Thoraval F, Roperch JP, Letulle S, Langella P, Corthier G, Tran Van Nhieu J, Furet JP: Microbial dysbiosis in colorectal cancer (CRC) patients. PLOS One 2011, 6:e16393

7. Skarin A, Sylwan J: Vaginal lactobacilli inhibiting growth of Gardnerella vaginalis, Mobiluncus and other bacterial species cultured from vaginal content of women with bacterial vaginosis. Acta pathologica, microbiologica, et immunologica Scandinavica Section B, Microbiology 1986, 94:399-403

8. Mancuso MS, Figueroa D, Szychowski JM, Paden MM, Owen J: Midtrimester bacterial vaginosis and cervical length in women at risk for preterm birth. Am J Obstet Gynecol 2011, 204(342):e341-e345.

9. Ness RB, Kip KE, Hillier SL, Soper DE, Stamm CA, Sweet RL, Rice P, Richter HE: A cluster analysis of bacterial vaginosis-associated microflora and pelvic inflammatory disease. Am J Epidemiol 2005, 162:585-590.

10. Larsson PG, Carlsson B: Does pre- and postoperative metronidazole treatment lower vaginal cuff infection rate after abdominal hysterectomy among women with bacterial vaginosis? Infect Dis Obstet Gynecol 2002, 10:133-140.

11. Martin DH: The microbiota of the vagina and its influence on women's health and disease. Am J Med Sci 2012, 343:2-9.

12. Gillet E, Meys JF, Verstraelen H, Bosire C, De Sutter P, Temmerman M, Broeck DV: Bacterial vaginosis is associated with uterine cervical human papillomavirus infection: a meta-analysis. BMC Infect Dis 2011, 11:10.

13. Guo YL, You K, Qiao J, Zhao YM, Geng L: Bacterial vaginosis is conducive to the persistence of HPV infection. Int J STD AIDS 2012, 23:581-584.

14. Dols JA, Reid G, Kort R, Schuren FH, Tempelman H, Bontekoe TR, Korporaal H, Van der Veer EM, Smit PW, Boon ME: PCR-based identification of eight Lactobacillus species and $18 \mathrm{hr}$-HPV genotypes in fixed cervical samples of South African women at risk of HIV and BV. Diagn Cytopathol 2012, 40:472-477.

15. Koshiol J, Lindsay L, Pimenta JM, Poole C, Jenkins D, Smith JS: Persistent human papillomavirus infection and cervical neoplasia: a systematic review and meta-analysis. Am J Epidemiol 2008, 168:123-137.

16. Castellsague $X$ : Natural history and epidemiology of HPV infection and cervical cancer. Gynecol Oncol 2008, 110:S4-S7.

17. Watts DH, Fazzari M, Minkoff H, Hillier SL, Sha B, Glesby M, Levine AM, Burk R, Palefsky JM, Moxley M, et al: Effects of bacterial vaginosis and other genital infections on the natural history of human papillomavirus infection in HIV-1-infected and high-risk HIV-1-uninfected women. J Infect Dis 2005, 191:1129-1139.

18. Nam KH, Kim YT, Kim SR, Kim SW, Kim JW, Lee MK, Nam EJ, Jung YW: Association between bacterial vaginosis and cervical intraepithelial neoplasia. J Gynecol Oncol 2009, 20:39-43.

19. Amann Rl, Ludwig W, Schleifer KH: Phylogenetic identification and in situ detection of individual microbial cells without cultivation. Microbio/ Rev 1995, 59:143-169.

20. Eckburg PB, Bik EM, Bernstein CN, Purdom E, Dethlefsen L, Sargent M, Gill SR, Nelson KE, Relman DA: Diversity of the human intestinal microbial flora. Science 2005, 308:1635-1638. 
21. Vasquez A, Jakobsson T, Ahrne S, Forsum U, Molin G: Vaginal lactobacillus flora of healthy Swedish women. J Clin Microbiol 2002, 40:2746-2749.

22. Zhou X, Bent SJ, Schneider MG, Davis CC, Islam MR, Forney L: Characterization of vaginal microbial communities in adult healthy women using cultivation-independent methods. Microbiology 2004, 150:2565-2573.

23. Duineveld BM, Rosado AS, van Elsas JD, van Veen JA: Analysis of the dynamics of bacterial communities in the rhizosphere of the chrysanthemum via denaturing gradient gel electrophoresis and substrate utilization patterns. Appl Environ Microbiol 1998, 64:4950-4957.

24. Ercolini D: PCR-DGGE fingerprinting: novel strategies for detection of microbes in food. J Microbiol Methods 2004, 56:297-314

25. Devillard E, Burton JP, Reid G: Complexity of vaginal microflora as analyzed by PCR denaturing gradient gel electrophoresis in a patient with recurrent bacterial vaginosis. Infect Dis Obstet Gynecol 2005, 13:25-31.

26. Smith BC, McAndrew T, Chen Z, Harari A, Barris DM, Viswanathan S, Rodriguez AC, Castle P, Herrero R, Schiffman M, Burk RD: The cervical microbiome over 7 years and a comparison of methodologies for its characterization. PLoS One 2012, 7:e40425.

27. Kim TK, Thomas SM, Ho M, Sharma S, Reich Cl, Frank JA, Yeater KM, Biggs DR, Nakamura N, Stumpf R, et al: Heterogeneity of vaginal microbial communities within individuals. J Clin Microbio/ 2009, 47:1181-1189.

28. Signoretto C, Bianchi F, Burlacchini G, Sivieri F, Spratt D, Canepari P: Drinking habits are associated with changes in the dental plaque microbial community. J Clin Microbiol 2010, 48:347-356.

29. Zijnge V, Welling GW, Degener JE, van Winkelhoff AJ, Abbas F, Harmsen HJ: Denaturing gradient gel electrophoresis as a diagnostic tool in periodontal microbiology. J Clin Microbiol 2006, 44:3628-3633.

30. Hummelen R, Fernandes AD, Macklaim JM, Dickson RJ, Changalucha J, Gloor GB, Reid G: Deep sequencing of the vaginal microbiota of women with HIV. PLoS One 2010, 5:e12078.

31. $Y u Z$ Z, Morrison M: Comparisons of different hypervariable regions of rrs genes for use in fingerprinting of microbial communities by PCR-denaturing gradient gel electrophoresis. Appl Environ Microbiol 2004, 70:4800-4806.

32. Suau A, Bonnet R, Sutren M, Godon JJ, Gibson GR, Collins MD, Dore J: Direct analysis of genes encoding 16S rRNA from complex communities reveals many novel molecular species within the human gut. Appl Environ Microbiol 1999, 65:4799-4807.

33. Walter J, Tannock GW, Tilsala-Timisjarvi A, Rodtong S, Loach DM, Munro K, Alatossava T: Detection and identification of gastrointestinal Lactobacillus species by using denaturing gradient gel electrophoresis and speciesspecific PCR primers. Appl Environ Microbiol 2000, 66:297-303.

34. Weisburg WG, Barns SM, Pelletier DA, Lane DJ: 16S ribosomal DNA amplification for phylogenetic study. J Bacteriol 1991, 173:697-703.

35. Vitali B, Pugliese C, Biagi E, Candela M, Turroni S, Bellen G, Donders GG, Brigidi P: Dynamics of vaginal bacterial communities in women developing bacterial vaginosis, candidiasis, or no infection, analyzed by PCR-denaturing gradient gel electrophoresis and real-time PCR. Appl Environ Microbiol 2007, 73:5731-5741.

36. Qu W, Jiang G, Cruz Y, Chang CJ, Ho GY, Klein RS, Burk RD: PCR detection of human papillomavirus: comparison between MY09/MY11 and GP5+/GP6+ primer systems. J Clin Microbiol 1997, 35:1304-1310.

37. Bollmann R, Mehes G, Torka R, Speich N, Schmitt C, Bollmann M: Human papillomavirus typing and DNA ploidy determination of squamous intraepithelial lesions in liquid-based cytologic samples. Cancer 2003, 99:57-62.

38. Eichner CA, Erb RW, Timmis KN, Wagner-Dobler I: Thermal gradient gel electrophoresis analysis of bioprotection from pollutant shocks in the activated sludge microbial community. Appl Environ Microbiol 1999, 65:102-109.

39. Boon N, Windt W, Verstraete W, Top EM: Evaluation of nested PCR-DGGE (denaturing gradient gel electrophoresis) with group-specific 16S rRNA primers for the analysis of bacterial communities from different wastewater treatment plants. FEMS Microbiol Ecol 2002, 39:101-112.

40. Hill TC, Walsh KA, Harris JA, Moffett BF: Using ecological diversity measures with bacterial communities. FEMS Microbiol Ecol 2003, 43:1-11.

41. Yamamoto T, Zhou X, Williams CJ, Hochwalt A, Forney LJ: Bacterial populations in the vaginas of healthy adolescent women. $J$ Pediatr Adolesc Gynecol 2009, 22:11-18.

42. Shi $Y$, Chen L, Tong J, Xu C: Preliminary characterization of vaginal microbiota in healthy Chinese women using cultivation-independent methods. J Obstet Gynaecol Res 2009, 35:525-532.
43. Castle PE, Hillier SL, Rabe LK, Hildesheim A, Herrero R, Bratti MC, Sherman ME, Burk RD, Rodriguez AC, Alfaro M, et al: An association of cervical inflammation with high-grade cervical neoplasia in women infected with oncogenic human papillomavirus (HPV). Cancer epidemiology, biomarkers \& prevention : a publication of the American Association for Cancer Research, cosponsored by the American Society of Preventive Oncology 2001, 10:1021-1027.

44. Head IM, Saunders JR, Pickup RW: Microbial Evolution, Diversity, and Ecology: A Decade of Ribosomal RNA Analysis of Uncultivated Microorganisms. Microb Ecol 1998, 35:1-21.

45. Polz MF, Cavanaugh CM: Bias in template-to-product ratios in multitemplate PCR. Appl Environ Microbiol 1998, 64:3724-3730.

46. Ling Z, Liu X, Chen X, Zhu H, Nelson KE, Xia Y, Li L, Xiang C: Diversity of cervicovaginal microbiota associated with female lower genital tract infections. Microb Ecol 2011, 61:704-714

47. Li Y, Ku CY, Xu J, Saxena D, Caufield PW: Survey of oral microbial diversity using PCR-based denaturing gradient gel electrophoresis. J Dent Res 2005, 84:559-564.

48. Fromin N, Hamelin J, Tarnawski S, Roesti D, Jourdain-Miserez K, Forestier N, Teyssier-Cuvelle S, Gillet F, Aragno M, Rossi P: Statistical analysis of denaturing gel electrophoresis (DGE) fingerprinting patterns. Environ Microbiol 2002, 4:634-643.

49. Lamont RF, Sobel JD, Akins RA, Hassan SS, Chaiworapongsa T, Kusanovic JP, Romero R: The vaginal microbiome: new information about genital tract flora using molecular based techniques. BJOG 2011, 118:533-549.

50. Antonio MA, Hawes SE, Hillier SL: The identification of vaginal Lactobacillus species and the demographic and microbiologic characteristics of women colonized by these species. J Infect Dis 1999, 180:1950-1956

51. Song YL, Kato N, Matsumiya Y, Liu CX, Kato H, Watanabe K: Identification of and hydrogen peroxide production by fecal and vaginal lactobacilli isolated from Japanese women and newborn infants. J Clin Microbiol 1999, 37:3062-3064.

52. Xiao BB, Liao QP: Analysis of diversity of vaginal microbiota in healthy Chinese women by using DNA-fingerprinting. Beijing da xue xue bao Y xue ban = Journal of Peking University Health sciences 2012, 44:281-287.

53. Cherpes TL, Hillier SL, Meyn LA, Busch JL, Krohn MA: A delicate balance: risk factors for acquisition of bacterial vaginosis include sexual activity, absence of hydrogen peroxide-producing lactobacilli, black race, and positive herpes simplex virus type 2 serology. Sex Transm Dis 2008, 35:78-83.

54. Marrazzo JM, Antonio M, Agnew K, Hillier SL: Distribution of genital Lactobacillus strains shared by female sex partners. J Infect Dis 2009 199:680-683.

55. Fethers K, Twin J, Fairley CK, Fowkes FJ, Garland SM, Fehler G, Morton AM, Hocking JS, Tabrizi SN, Bradshaw CS: Bacterial vaginosis (BV) candidate bacteria: associations with BV and behavioural practices in sexuallyexperienced and inexperienced women. PLoS One 2012, 7:e30633.

56. Rodriquez Jovita M, Collins MD, Sjoden B, Falsen E: Characterization of a novel Atopobium isolate from the human vagina: description of Atopobium vaginae sp. nov. Int J Syst Bacteriol 1999, 49 Pt 4:1573-1576.

57. Menard JP, Fenollar F, Henry M, Bretelle F, Raoult D: Molecular quantification of Gardnerella vaginalis and Atopobium vaginae loads to predict bacterial vaginosis. Clinical infectious diseases: an official publication of the Infectious Diseases Society of America 2008, 47:33-43.

doi:10.1186/1471-2334-13-271

Cite this article as: Gao et al:: Comparison of the vaginal microbiota diversity of women with and without human papillomavirus infection: a cross-sectional study. BMC Infectious Diseases 2013 13:271. 